\title{
Breaking down the language of racism: a computerised linguistic analysis of racist groups' self-defining online statements
}

\begin{abstract}
The Internet represents a powerful tool for racist groups to achieve their collective goals - i.e., disseminating racist ideologies, increasing their support base, and enhancing their transnational influence. Their online presence is carefully and strategically crafted as it often constitutes their first point of contact with potential supporters. To identify linguistic markers or racist (online) communication and key presentational strategies of racist groups, we examine the language they use when describing their self-defining beliefs on their websites. A dataset of group online statements of racist self-defining beliefs $(N=102)$ was analysed using a computerised linguistic analysis software; we compared this dataset with a baseline of neutral texts $(N=12,173)$. We found that online selfdefining statements of racist groups were characterised by greater use of divisive language and a stronger focus on collective identity. We identified an increased use of religion and anger words, and reduced use of sadness and cognitive complexity words. We conclude by discussing implications of these findings for designing policies aiming to counteract the harmful societal effects of racist groups.
\end{abstract}




\section{Breaking down the language of cyber-racism: a computerised linguistic analysis of racist groups' self-defining online statements}

\section{Introduction}

Purveyors of racist hate have a long history of using the latest communication media to spread bigotry and prejudice. For years, racist groups used written materials, radio broadcasts and public television networks (Anti-Defamation League, 2001). More recently, they were early adopters of Internet technology (Gerstenfeld et al., 2003; Hamm, 1993), becoming increasingly skilled in using the Internet to further their goals. Racist groups utilise a diverse array of virtual places, including social networking sites, chat rooms, discussion boards and their own websites to express and spread their views and ideologies, sell promotion merchandise, and recruit new members (Douglas et al., 2005). The Internet is an effective tool for racist groups as it allows them to reach larger audiences faster, and communicate anonymously and at a lower cost than they ever could before the advent of the Internet (Daniels, 2013; Hale, 2012; see also McNamee et al., 2010). As a result, they have been able to use the Internet technologies to their advantage at alarming rates and with concerning consequences (Hale, 2012).

More specifically, the Internet helps racist groups in achieving at least three broad goals. The first goal involves using the Internet to share racist messages to broad audiences, often with the intent of 'educating' the public (Caiani \& Parenti, 2010; Daniels, 2009; Gerstenfeld et al., 2003). Second, racist groups use the Internet to boost their communities (in both numbers and internal cohesion) by enabling them to attract new members and strengthen the commitment of existing members (Adams \& Roscigno, 2005; Chau \& Xu, 2006; Weaver, 2012). To achieve this, they use various persuasion strategies (Lee \& Leets, 2002; Weatherby \& Scoggins, 2010), humour (Billig, 2001; Weaver, 2012), and subtle reinterpretations of the social context (Douglas et al., 2005). Third, racist groups use the Internet to increase their global influence by building a sense of transnational 
collective identity (Adams \& Roscigno, 2005; Burris et al., 2000; Gerstenfeld et al., 2003) that allows them to develop perceptions of significance across national boundaries. They seek to achieve this goal by connecting to similar racist groups in other countries (Burris et al., 2000), by facilitating communication between spatially disconnected racist individuals (Simi \& Futrell, 2006), and by providing isolated racist individuals with virtual communities of support (as for example, in the case of notorious white supremacist Anders Breivik in Norway).

There is evidence suggesting that racist groups are becoming more sophisticated in manipulating language to present their messages as legitimate and mainstream (Daniels, 2009; 2013; Douglas et al., 2005; Faulkner \& Bliuc, 2015). In particular, these groups seem to be highly creative in using strategies which avoid using language that would openly advocate hostility and conflict (Douglas et al., 2005). These strategies are aimed to both avoid having their websites closed due to legal infringements and increase attractiveness to potential recruits, targeting a broader audience of undecided individuals with moderate racist views.

Currently, the field has collected a substantial amount of evidence regarding various discursive strategies used by racist groups online (e.g., Atton, 2006; Billig, 2001; Douglas et al., 2005; Erjavec \& Kovacic, 2012; Tynes et al., 2004); however, researchers payed far less attention to the actual language used by racist groups when they are describing their goals, values and beliefs or when they are self-promoting online. As such, there is no known research to date that examined language use by racist groups when presenting their self-defining beliefs online. This gap in research exists despite evidence showing that examining such language use could provide insights into these groups' psychological processes, substantive concerns and presentational strategies (Tausczik \& Pennebaker, 2010). Our objective here is to remedy this by examining the language racist groups use when presenting their group goals and beliefs on the Internet, and to identify specific markers of racist language online. We do this by comparing the self-defining language of racist groups with a large body of neutral language. We focus on exploring language as a collective product of these 
groups with the goal of identifying the underpinning psychological states of producers of online racist language (von Hippel et al., 2009; Tausczik \& Pennebaker, 2010).

\section{Language use as an indicator of psychological states and concerns}

The idea that the words individuals use reflect underlying psychological states or concerns has a long history in psychology. Freud (1901) believed that linguistic errors - slips of the tongue - revealed hidden emotions, intentions and thoughts. Similarly, Gottschalk and colleagues (Gottschalk \& Gleser, 1969; Gottschalk et al., 1958) developed a method to identify hidden psychological states including anxiety, hostility, social alienation and personal disorganisation by analysing recorded speech. More recently, Pennebaker and colleagues developed a computerised method to analyse and categorise language (Pennebaker et al., 2007a; 2015), and have shown that language use reflects a variety of psychological states, social processes, and personal concerns (for a review, see Tausczik \& Pennebaker, 2010).

One of the ways that language has been shown to reflect psychological states relates to emotions. Specifically, the use of emotion-related words has been found to correlate with individuals' moods, even when those words are not being used to refer to the individuals' own emotions. For example, the way a text is constructed was shown to influence readers' perceptions about the writer's emotions. That is, simple counts of the number of positive (e.g., happy, joyful) and negative (e.g., angry, sad) emotion words in a text have been found to correlate strongly with independent raters' perceptions of positive and negative emotions, respectively, in those texts (Bantum \& Owen, 2009; Pennebaker, Mayne \& Francis, 1997; Pennebaker \& Francis, 1996). Similarly, research from the perspective of the communicators shows that individuals who use more positive emotion words relative to negative emotion words, overcome trauma more effectively than individuals who use less positive emotion words (Pennebaker et al., 1997; Pennebaker \& Francis, 1996). 
Language use can also indicate individuals' depth of thinking. The use of exclusive words (e.g., but, without, exclude) was shown to indicate that an individual is making distinctions and has been argued to be indicative of cognitive complexity (Pennbaker \& King, 1999; Slatcher et al., 2007; Tausczik \& Pennebaker, 2010). The use of exclusive words was found to correlate positively with Openness to Experience (Pennebaker \& King, 1999) - a personality dimension that predicts intellectual curiosity and a willingness to try new things (McCrae and John, 1992) - and to load positively on a factor-analytically derived linguistic measure of what has been variously described as “making distinctions” (Pennebaker \& King, 1999) or 'cognitive complexity' (Slatcher et al., 2007). Other word categories may also indicate depth of thought - for example, among college students, greater use of insightful words (e.g., know, consider, etc.) was found to predict higher grades (Pennebaker \& Francis, 1996).

Language use can also reflect social concerns such as a focus on community and reliance on strong group ties. Linguistic analyses of online text revealed that the use of first person plural words (e.g., we and us) increases when groups are responding to tragedies such as 9/11 (Cohn et al., 2004; Mehl \& Pennebaker, 2003), the Death of Princess Diana (Stone \& Pennebaker, 2002), or the Texas AandM Bonfire tragedy in which 12 students were killed (Gortner \& Pennebaker, 2003). In the context of online communities of recovery from drug and alcohol addiction, the increased use of we and affiliation words (reflecting identification with the recovery community) was found to predict positive recovery outcomes (Bliuc, Best, Iqbal \& Upton, 2017; Bliuc, Best, Beckwith \& Iqbal, 2016). Additionally, individuals engage in more group discussions (i.e., discussions with three or more individuals) immediately after tragedies than at other times (Mehl \& Pennebaker, 2003), thus indicating that the increased use of we after tragedies reflects stronger reliance on group ties. Further still, experimental research has shown that individuals who are directed to describe a friendship using the word we report higher levels of closeness and intimacy than individuals who are directed to describe the friendship using the friend's name (e.g., Sarah and I) (Brewer \& Gardner, 1996). 
Word use can also reveal other concerns on which individuals are focussing their attention. For example, the use of words relating to religion (e.g., church, mosque), death (e.g., bury, coffin) or money (e.g., cash, owe) can indicate that attention is being focussed on each of these areas (Tausczik \& Pennebaker, 2010). Similarly, first-person pronoun (e.g., I, me) use can indicate that individuals are focussing attention on themselves. For example, Gunsch, Brownlow, Haynes, and Mabe (2000) found that political candidates' advertisements included more first-person pronouns when the advertisements were positive than when they were negative.

\section{Sending the right message: online self-defining statements of racist groups}

Online statements of group beliefs are designed to express key attributes and ideological messages that are deemed as representative for the group, so they are likely to be developed either collaboratively or by representative (or prototypical) members of the group. That is, they provide opportunities for 'entrepreneurs of identity' such as the leaders of racist groups to present a specific vision of what it means to be a member of that group (Haslam et al., 2011). These statements are designed with intent of increasing the desirability of the group to potential new members and of boosting the sense of belonging to a strong, cohesive community in existing members. Thus, in a sense, analysing the language contained in such statements could represent a particularly useful strategy to investigate specific intragroup dynamics operating within broader groups of supporters of racism.

Also, group self-defining online statements are in most cases the first point of contact for the group with sympathisers and potential recruits. At the same time, these statements may also be the most monitored by authorities, so they need to be framed in such a way that is both powerful and subtle. This would suggest that these statements are highly strategical documents shaped by the specific goals of the group, so it is likely that they required a considerable amount of time to be 'calibrated' for their target audience. However, rather than analysing these statements to identify 
their strategic use and explicit goals (as done in previous studies), we adopt the different approach of analysing the language use to identify its implicit underpinning psychological dimensions.

\section{Present study}

To identify distinctive linguistic markers of online self-descriptions of racist group beliefs we use the computerised text analysis program, Linguistic Inquiry Word Count (LIWC, Pennebaker et al. 2007a). As outlined above, identifying such markers would indicate the psychological states and concerns of the individuals involved in the racist groups, and thus provide us with insights into what is behind the presentational strategies used by racist groups when they present themselves on their websites. To identify these markers, we compare the language in used in self-defining statements with neutral language extracted from a large corpus of text previously used in other studies as 'baseline language' (control group).

\section{Method}

\section{Text samples}

We collected a sample of racist self-descriptions from the websites of American and Australian racist organisations. The sample included a total of 102 statements describing each group's beliefs and ideology. Of these, 88 were made by American organisations and 14 were made by Australian organisations. The statements sampled espoused neo-Nazi $(n=17)$, anti-immigrant $(n=9)$, antiMuslim $(n=24), \mathrm{Ku}$ Klux Klan $(n=17)$, and white nationalist $(n=35)$ ideologies. The SPLC is a civil rights law firm that maintains a list of active US-based hate groups. Our selection of websites was based on the online resources provided by the Southern Poverty Law Center (SPLC, 2016). Many groups listed in the SPLC listings did not maintain websites that contained self-defining statements and were thus not included in our sample. To identify American racist group statements, the names of all hate groups designated by SPLC as neo-Nazi, anti-immigrant, anti-Muslim, Ku Klux 
Klan or white nationalist were individually entered into Google, and relevant websites were then examined to find pages that outlined each group's core beliefs. Australian racist group statements of beliefs were collected by examining all active Australian websites listed in Franklin's (2010) directory of hate groups, and by conducting Google searches relating to Australian racist and hate groups. These web searches were repeated to the point of saturation, meaning that no further racist groups that maintained active websites that contained statements of group beliefs could be found.

A corpus of 12,173 texts from previous language studies was also collected so that the unique linguistic markers of racist belief statements could be identified by comparing the language used in such statements with the language used in a corpus of neutral comparison documents. This corpus included blog posts, scientific articles, novels, transcribed examples of natural speech, and written responses collected in experiments that asked participants to write about either emotional or quotidian topics. Similar comparative approaches have been used to identify the markers of presidential (Slatcher et al., 2007), deceptive (Newman et al., 2003), and depressed (Rude et al., 2004) language.

\section{Analytic strategy}

All the texts collected were analysed using LIWC software. LIWC searches each text for over 2000 words or word stems that have previously been categorised into 80 different linguistic categories. The categories include standard function words (e.g., personal pronouns, articles, verbs, conjunctions), emotion words (e.g., positive emotions, anger, sadness), cognitive words (e.g., cause, know), and a variety of personal concerns (e.g., religion, money, death). LIWC then calculates the rate that each word category is used in each text. For example, LIWC output may indicate that $2.4 \%$ of all words in a given text file were third person pronouns, and 5.6\% were positive emotion words. LIWC categories have been validated (e.g. Bantum \& Owen, 2009; Pennebaker et al., 2007b; Tausczik \& Pennebaker, 2010) and are widely used in research on social and personality psychology 
(for a review, see Tausczik \& Pennebaker, 2010). Although the LIWC program computes statistics for 81 linguistic categories, based on previous studies, only 20 categories were retained for the current study. Of these 20 categories, 5 have been associated with personal and social identity (Davis \& Brock, 1975; Gunsch et al., 2000; Sillars et al., 1997; Cohn et al., 2004), 6 indicated cognitive processes (Pennebaker \& King, 1999; Pennebaker \& Francis, 1996), 3 indicated personal concerns (Tausczik \& Pennebaker, 2010), and 6 indicated the presence of emotions (Bantum \& Owen, 2009; Pennebaker et al., 1997; Pennebaker \& Francis, 1996).

In addition to analysing these 20 raw LIWC categories, we also included a composite linguistic measure of cognitive complexity. Past research has shown that cognitively complex language is characterised by higher usage of exclusive words (e.g., but, exclude), tentative words (e.g., maybe, perhaps), negations (e.g., not, never) and discrepancies (e.g., should, would), and lower usage of inclusive words (e.g., and, include) (Pennebaker \& King, 1999; Slatcher et al., 2007). Thus, following past research (Slatcher et al., 2007) we computed a linguistic measure of cognitive complexity by summing the $z$-scores of the exclusive, tentative, negations, and discrepancies categories, and subtracting the inclusive category, $\alpha=.68$.

\section{Results}

\section{Preliminary analyses}

We first tested for differences between American and Australian racist texts using Welch's ttests with Bonferroni corrections. Results revealed no significant differences on any of the 20 linguistic categories included in the current study, $p \mathrm{~s}>.99$. Thus, American and Australian racist texts were combined into one category for further analysis. In the interests of full disclosure, in an exploratory phase of this research we tested for differences on all but three spoken word categories (nonfluences, fillers, and assent). To avoid type I errors, all $p$-values reported in this paper have been adjusted for these additional comparisons using Bonferroni corrections (Abdi, 2007). 


\section{Main analyses}

A series of Welch's t-tests with Bonferroni corrections were computed to test for linguistic differences between racist self-descriptions and control texts. Results are reported in Table 1. $<<$ Table 1 about here $>>$

Racist self-descriptions also contained fewer words related to cognitive complexity than comparison texts. Specifically, racist self-descriptions scored lower on the composite cognitive complexity measure, $t(104.77)=-13.73, p<.001, d=-1.08$, and the pattern of results on each of the individual linguistic categories contained in that measure were consistent with the claim that racist selfdescriptions contained less cognitively-complex language.

Racist self-descriptions also differed from comparison texts in the extent to which they used words associated with concern for different personal issues. In particular, racist self-descriptions contained more words related to religion, $t(101.13)=8.02, p<.001, d=-1.08$ than control texts. No significant differences emerged in the extent to which words relating to money, $t(102.69)=3.29, p=$ $.106, d=0.33$, or death, $t(102.07)=3.41, p=.073, d=0.37$, were found.

Differences were found in the extent to which some categories of emotion words were used. Racist self-descriptions contained significantly more anger words, $t(102.57)=6.52, p<.001$, $d=0.66$, and significantly less sadness words, $t(106.12)=-4.41, p=.002, d=-0.31$, than comparison texts. No significant differences emerged on any of the other emotion categories, $p \mathrm{~s}<$ .323.

\section{Discussion}

Whereas much research on cyber-racism has focused on the discursive strategies used by racist groups, less attention has been paid to the actual language used when racist groups are describing themselves online or they are self-promoting. Analysing such language represents an opportunity to go beyond the self-presentation strategies that these groups employ to uncover the psychological 
states, concerns, and more implicit strategies used by racist groups when presenting their core beliefs, values and goals online. This approach has some distinct advantages; it allows for the analysis of large samples of textual data, it is objective, transparent and easily replicable, and it has high external validity (von Hippel et al., 2009; Grimmer \& Stewart, 2013). In this way, it represents a promising additional method for research on cyber-racism that both complements and, in some respects, goes beyond the discourse analysis techniques that have been commonly used in existing research.

This study identified powerful effects by analysing a large number of text samples with LIWC. First, we found that online self-defining statements of racist groups contained more first- (e.g. 'us', 'we') and third-person (e.g. 'them', 'they') plural pronouns, fewer first- (e.g. 'I', 'me'), and third-person (e.g. 'you', 'your') singular pronouns, and fewer second-person (e.g. 'she', 'him') pronouns than comparison texts. Reading these findings as complementing previous work on the theory of these groups (Douglas et al., 2005), they seem to indicate that the language analysed incorporates an 'us versus them' divisive rhetoric. They also indicate that racist groups display a strong focus on their collective identity when describing online what they stand for. Past research has found that the use of first- and third-person plural pronouns often signifies the existence of strong group ties and a strong focus on collective identity (Cohn et al., 2004; Agnew et al., 1998). Thus, the finding provides additional support for the claim that racist groups use their website's selfdescriptive statements to build and enhance a sense of belonging to a collective identity (Adams \& Rosigno, 2005; Burris et al., 2000) that is contrasted to opposing identities of the outgroup (through the use of 'us vs. them' type of language).

Second, racist group self-defining statements contained fewer words associated with cognitive complexity than comparison documents. This finding implies that racist groups tend to present their beliefs in relatively simple, "black and white" ways, rather than making sophisticated distinctions between different ideas and integrating perspectives to identify key similarities 
(Pennbaker \& King, 1999; Slatcher et al., 2007; Tausczik \& Pennebaker, 2010). Additionally, this finding may be indicative of a persuasion strategy being used by racist groups to attract new members. Indeed, research has indicated that simple messages tend to be more persuasive than complex messages when the group or individual presenting the message has a lower status, as most racist groups do (Hafer et al., 1996; also see Lowrey, 1998). The use of simpler language in racist self-defining statements may serve to increase their persuasiveness, and may therefore be favoured by racist groups when presenting their beliefs online. Alternatively, the relatively low level of cognitive complexity in racist texts may simply indicate that racists hold relatively simple, more black-and-white views. Indeed, past research has shown that lower cognitive ability predicts greater prejudice (Hodson \& Busseri, 2012), that racists tend to have lower tolerance of ambiguity (Sidanius, 1978; van Hiel et al., 2004; also see Jost et al., 2003), and that racists explain behaviour in lesscomplex ways than non-racists (Tam et al., 2008). This is the first study to show that racist groups use relatively less cognitively complex language than neutral comparison texts, and suggests a promising avenue for future research investigating whether this language is merely reflective of the low-complexity views held by racist groups, or reflective of an as yet unidentified persuasion strategy used by racist groups online.

Third, racist group self-defining statements included more religion words (e.g., church, mosque) than comparison texts, indicating that racist groups use religion to a significant degree when describing their beliefs, values and goals online. Existing research using qualitative techniques, such as thematic analysis of interview data, has shown that racist groups use religion to strengthen white racist identities and present white racial superiority as divinely sanctioned (Adams \& Rosigno, 2005; Barkun, 1997; Dobratz, 2001; McNamee et al., 2010). Adams and Rosigno (2005), for example, analysed documents from white nationalist groups' websites and found that both Ku-Klux Klan and neo-Nazi groups used religion to foster identification with white racial groups. The current study, not only finds support for this claim using a different method, but also broadens these findings by 
showing that, on average, religion is used more frequently across a wide range of racist groups than it is in neutral comparison texts.

Fourth, significant differences in emotion expression were found between racist group selfdefining online statements and neutral comparison documents. Specifically, racist groups' statements contained more anger and less sadness than neutral texts. Although the role of emotions in promoting collective action has received substantial attention (e.g., Mackie et al., 2000; van Zomeren et al., 2004, Bliuc et al., 2015), no research so far has explicitly investigated how racist groups use emotions as part of their online strategies to promote group identification and mobilise collective action in support of their goals. Past research has characterised anger as a high-arousal emotion that motivates action against the target of the anger (Lazarus, 1991; Iyer and Leach, 2010; Mackie et al., 2000). Anger as an expression of perceived injustice has been also consistently shown to be an antecedent of collective action mobilisation in many socio-political contexts, in particular when a relevant collective identity is also activated as part of the 'group consciousness' (Bliuc et al., 2015; Duncan, 2012). Relative to anger, sadness has been characterised as a less action-oriented emotion, and has been shown to predict action tendencies to avoid, rather than confront, outgroups (Crisp et al., 2007). The finding that racist group self-defining statements contain more anger and less sadness than comparison texts further supports the claim that anger is driver of collective action and can be used to unite and energise supporters. One interpretation of this finding is that anger may have driven collective action in the form of contributing to producing the content on the racist group websites (likely by an activist or a full member of these groups).

A complementary interpretation of this finding suggests that racist groups may be using anger on their websites to mobilise action on their behalf by motivating inactive racist sympathisers to become active members of racist groups or boosting intentions to participate in offline action in existing members. For this reason, future research should investigate the extent to which anger 
motivates individuals to become active in racist groups, and the extent to which such groups use anger to motivate inactive sympathisers or current members to become active 'in real life'.

Despite the distinct advantages of the computerised text analysis utilised in this study, the method is not without limitations. One limitation is that simple word counts inevitably cannot capture the complexities of language. LIWC cannot detect sarcasm, irony nor differentiate between different uses of the same word. For example, depending on the context in which it is used, the word 'object' can operate as a noun or a verb, each having very different meanings that are not appreciated by LIWC. Despite this limitation, past research has consistently shown that LIWC categories reflect meaningful psychological states and personal concerns in many different contexts (for a review, see Tausczik \& Pennebaker, 2010). Given its unique strengths - such as high transparency and external validity, easy replicability, and its ability to quickly analyses of large samples of textual data (von Hippel et al., 2009; Grimmer \& Stewart, 2013) - computerised text analysis can usefully complement more traditional methods, and seems particularly well-suited to capture key aspects of the dynamic interactions on online communication platforms.

\section{Conclusion}

Overall, the present research demonstrates that language is used differently in online self-defining statements of racist groups compared to neutral language. That is, our study indicates that racist groups' online self-defining statements have distinct linguistic characteristics that reflect such groups' psychological states and concerns, and indirectly uncover their presentational strategies. Consistent with past research using qualitative analyses of their online language, we found that racist groups focus strongly on group ties and collective identity, and often use on religious concepts when presenting their core beliefs on their websites. We also found that racist groups use words associated with low cognitive complexity, which may suggest more than that racist people have black and white views - that is, it may indicate the deliberate use of specific persuasion strategies. Their language is 
underpinned by distinct emotions such as anger, indicating promising new directions for research on how racists use the Internet to express, spread their views, and mobilise support.

Racist groups undermine contemporary diverse societies by creating intergroup division and mistrust, thus escalating intergroup tensions. Recently, in many Western democracies, we have seen an increase in populism manifested in unprecedented levels of public support for far-right groups with a racist agenda (Inglehart, \& Norris, 2016). To be able to counteract the societal influence of these groups, we need to first fully understand (possibly implicit) communication strategies and psychological mechanisms which may explain their public appeal. Our research represents an initial step in that direction - it sets a platform for further investigation of how racists groups use online communication techniques to exploit public's current fears and insecurities.

From a methodological point of view, our findings demonstrate the power of LIWC as a valuable research tool in the context of online social interaction. Using LIWC to analyse website content can identify the psychological processes and presentational strategies being used by racist (and other types of) groups; a task that is increasingly important as racist groups have been consistently progressing in finding new ways to exploit the Internet to achieve their goals.

\section{Acknowledgements}

The authors thank James Pennebaker for sharing the dataset of neutral documents. Acknowledgements regarding funding sources are removed for peer-review.

\section{References}

Abdi, H. (2007). The Bonferroni and Šidák corrections for multiple comparisons. In NJ Salkind (ed) Encyclopedia of measurement and statistics. Thousand Oaks, CA: SAGE Publications.

Adams, J., \& Roscigno, V.J. (2005). White supremacists, oppositional culture and the world wide web. Social Forces, 84(2), 759-78. 
Agnew, C.R., Van Lange, P.A., Rusbult, C.E., \& Langston, C.A. (1998). Cognitive interdependence: Commitment and the mental representation of close relationships. Journal of Personality and Social Psychology, 74(4), 939-54.

Anti-Defamation League (2001). Poisoning the web: Hatred online. Retrieved 8 November, 2016 from http://archive.adl.org/poisoning_web/net_hate_tool.html.

Atton, C. (2006). Far-right media on the Internet: Culture, discourse and power. New Media and Society, 8(4), 573-587.

Bantum, E.O., \& Owen, J.E. (2009). Evaluating the validity of computerized content analysis programs for identification of emotional expression in cancer narratives. Psychological Assessment, 21(1), 79-88.

Barkun, M. (1997). Religion and the Racist Right: The Origins of the Christian Identity Movement. Chapel Hill, NC: University of North Carolina Press.

Bliuc, A. M., McGarty, C., Thomas, E. F., Lala, G., Berndsen, M., \& Misajon, R. (2015). Public division about climate change rooted in conflicting socio-political identities. Nature Climate Change, 5(3), 226-229.

Bliuc, A. M., Best, D., Iqbal, M., \& Upton, K. (2017). Building addiction recovery capital through online participation in a recovery community. Social Science \& Medicine.

Bliuc, A. M., Best, D., Beckwith, M., \& Iqbal, M. (2016). Online support communities in addiction recovery. Addiction, Behavioral Change and Social Identity: The Path to Resilience and Recovery, p.137.

Billig, M. (2001). Humour and hatred: The racist jokes of the Ku Klux Klan. Discourse and Society $12(3), 267-89$.

Brewer, M.B., \& Gardner W. (1996). Who is this 'we'?: Levels of collective identity and self representations. Journal of Personality and Social Psychology, 71(1), 83-93. 
Burrisa, V., Smith E., \& Strahm A. (2000). White supremacist networks on the Internet. Sociological Focus, 33(2), 215-235.

Caiani, M., \& Parenti, L. (2010). The dark side of the web: Italian right-wing extremist groups and the Internet. Southern European Society and Politics, 14(3), 273-94.

Chau, M., \& Xu, J. (2006). Mining communities and their relationships in blogs: A study of online hate groups. International Journal of Human-Computer Studies, 65(1), 57-70.

Cohn, M.A., Mehl, M.R., \& Pennebaker, J.W. (2004). Linguistic markers of psychological change surrounding September 11, 2001. Psychological Science 15(1), 687-693.

Crisp, R.J., Heuston, S., Farr, M.J., \& Turner, R.N. (2007). Seeing red or feeling blue: Differentiated intergroup emotions and ingroup identification in soccer fans. Group Processes and Intergroup Relations, 10(1), 9-26.

Daniels, J. (2009). Cloaked websites: propaganda, cyber-racism and epistemology in the digital era. New Media \& Society, 11(5), 659-683.

Daniels, J. (2013). Race and racism in Internet studies: A review and critique. New Media \& Society, 15(5), 695-719.

Davis, D., \& Brock, T.C. (1975). Use of first person pronouns as a function of increased objective self-awareness and performance feedback. Journal of Experimental Social Psychology, 11(4), 381-388.

Dobratz, B.A. (2001). The Role of Religion in the Collective Identity of the White Racialist Movement. Journal for the Scientific Study of Religion, 40(2), 287-301.

Douglas, K.M., McGarty, C.A., Bliuc, A.-M., \& Lala, G. (2005). Understanding cyberhate. Social Science Computer Review, 23(1), 68-76.

Duncan, L. E. (2012). The psychology of collective action. In The Oxford handbook of personality and social psychology. 
Erjavec, K. \& Kovacic, M.P. (2012). 'You don't understand, this is a new war!' Analysis of hate speech in news websites' comments. Mass Communication and Society, 15(6), 899-920.

Faulkner, N., \& Bliuc, A.-M. (2016). 'It's okay to be racist': moral disengagement in online discussions of racist incidents in Australia. Ethnic and Racial Studies, 39(14), 2545-2563.

Flores-Yeffal, N.Y., Vidales, G., \& Plemons, A. (2011). The Latino cyber-moral panic processes in the United States. Information, Communication and Society, 14(4), 568-89.

Franklin, R.A. (2010). The Hate Directory. Accessed October 5, 2016.

http://www.hatedirectory.com.

Freud, S. (1901). Psychopathology of everyday life. New York: Basic Books.

Gerstenfeld, P.B., Grant, D.R., \& Chiang, C.P. (2003). Hate online: A content analysis of extremist Internet sites. Analyses of Social Issues and Public Policy, 3(1), 29-44.

Gottschalk, L.A. \& Gleser, G.C. (1969) The measurement of psychological states through the content analysis of verbal behavior. Berkeley: University of California Press.

Gottschalk, L.A., Gleser, G.C., Daniels, R.S., \& Block, S. (1958). The speech patterns of schizophrenic patients: A method of assessing relative degree of personal disorganization and social alienation. Journal of Nervous and Mental Disease, 127(2), 153-66.

Gortner, E.M. \& Pennebaker, J.W. (2003). The archival anatomy of a disaster: Media coverage and community-wide health effects of the Texas AandM bonfire tragedy. Journal of Social and Clinical Psychology, 22(5), 580-603.

Gunsch, M.A., Brownlow, S., Haynes, S.E., \& Mabe, Z. (2000). Differential linguistic content of various forms of political advertising. Journal of Broadcasting and Electronic Media, 44(1), 27-42.

Hafer, C.L., Reynolds, K.L., \& Obertynski, M.A. (1996). Message comprehensibility and persuasion: Effects of complex language in counter-attitudinal appeals to laypeople. Social Cognition, 14(4), 317-337. 
Hale, W.C. (2012). Extremism on the World Wide Web: A research review. Criminal Justice Studies, 25(4), 343-356.

Hamm, M.S. (1993). American skinheads: The criminology and control of hate crime. Westport, CT: Praeger.

Haslam, S.A., Reicher, S.D., \& Platow, M.J. (2011). The new psychology of leadership: Identity, influence and power. New York, NY: Psychology Press.

Hodson, G., \& Busseri, M.A. (2012). Bright minds and dark attitudes: Lower cognitive ability predicts greater prejudice through right-wing ideology and low intergroup contact. Psychological Science, 23(2), 187-95.

Inglehart, R., \& Norris, P. (2016). Trump, Brexit, and the rise of populism: Economic have-nots and cultural backlash. HKS Faculty Research Working Paper Series RWP16-026.

Iyer, A., \& Leach, C.W. (2010). Helping disadvantaged out-groups challenge unjust inequality: The role of group-based emotions. In Stürmer S and Snyder M (eds) The Psychology of Prosocial Behavior: Group Processes, Intergroup Relations, and Helping. West Sussex: WileyBlackwell.

Jost, J.T., Glasser J., Kruglanski, A.W., \& Sulloway, F.J. (2003). Political conservatism as motivated social cognition. Psychological Bulletin, 129(3), 339-75.

Lazarus, R.S. (1991). Emotion and adaption. New York: Oxford University Press.

Lee, E. \& Leets, L. (2002). Persuasive storytelling by hate groups online: Examining its effects on adolescents. American Behavioral Scientist, 45(6), 927-57.

Lowrey, T.M. (1998). The effects of syntactic complexity on advertising persuasiveness. Journal of Consumer Psychology, 7(2), 187-206.

Mackie, D.M., Devos, T., \& Smith, E.R. (2000). Intergroup emotions: Explaining offensive action tendencies in an intergroup context. Journal of Personality and Social Psychology, 79(4), 602-16. 
McNamee, L.G., Peterson, B.L., \& Pena, J. (2010). A call to educate, participate, invoke and indict: Understanding the communication of online hate groups. Communication Monographs, 77(2), 257-80.

Mehl, M.R., \& Pennebaker, J.W. (2003). The sounds of social life: A psychometric analysis of students' daily social environments and natural conversations. Journal of Personality and Social Psychology, 84(4), 857-70.

Newman, M.L., Pennebaker, J.W., Berry, D.S., \& Richards, J.M. (2003). Lying words: Predicting deception from linguistic styles. Personality and Social Psychology Bulletin, 29(5), 665-75.

Pennebaker, J. W., Boyd, R. L., Jordan, K., \& Blackburn, K. (2015). The development and psychometric properties of LIWC2015.

Pennebaker, J.W., Booth, R.J., \& Francis, M.E. (2007a). Linguistic Inquiry and Word Count: LIWC [Computer software]. Austin, TX: LIWC.net

Pennebaker, J.W., Chung, C.K., Ireland, H., Gonzales, A., \& Booth, R.J. (2007b). The development and psychometric properties of LIWC2007. Austin, TX: LIWC.net.

Pennebaker, J.W., \& Francis, M.E. (1996). Cognitive, emotional, and language processes in disclosure. Cognition and Emotion, 10(6), 601-626.

Pennebaker, J.W., \& King, L.A. (1999). Linguistic styles: Language use as an individual difference. Journal of Personality and Social Psychology, 77(6), 1296-1312.

Pennebaker, J.W., Mayne, T.J., \& Francis, M.E. (1997). Linguistic predictors of adaptive bereavement. Journal of Personality and Social Psychology, 73(4), 863-71.

Rude, S.S., Gortner, E.M., \& Pennebaker, J.W. (2004). Language use of depressed and depressionvulnerable college students. Cognition and Emotion, 18(8), 1121-1133

Sidanius, J. (1978). Intolerance of ambiguity and socio-politico ideology: A multidimensional analysis. European Journal of Social Psychology, 8(2), 215-235. 
Sillars, A., Shellen, W., McIntosh, A., \& Pomegranate, M. (1997). Relational characteristics of language: Elaboration and differentiation in marital conversations. Western Journal of Communication, 61(4), 403-22.

Simi, P., \& Futrell, R. (2006). Cyberculture and the endurance of white power activism. Journal of Political and Military Sociology, 34(1), 115-42.

Slatcher, R.B., Chung, C.K., Pennebaker, J.W., \& Stone, L.D. (2007) Winning words: Individual differences in linguistic style among U.S. presidential and vice presidential candidates. Journal of Research in Personality, 41(1), 63-75.

SPLC. (2016). Intelligence Files. Accessed April 4, 2016. http://www.splcenter.org/getinformed/intelligence-files

Stone, L.D., \& Pennebaker, J.W. (2002) Trauma in real time: Talking and avoiding online conversations about the death of Princess Diana. Basic and Applied Social Psychology, 24(3), 173-83.

Tam, K.P., Au, A., \& Leung, A.K.Y. (2008). Attributionally more complex people show less punitiveness and racism. Journal of Research in Personality, 42(4), 1074-81.

Tausczik, Y.R., \& Pennebaker, J.W. (2010). The psychological meaning of words: LIWC and computerized text analysis methods. Journal of Language and Social Psychology, 29(1), 2454.

Tynes, B.M., Reynolds, L., \& Greenfield, P.M. (2004). Adolescence, race and ethnicity on the Internet: A comparison of discourse in monitored vs. unmonitored chat rooms. Applied Developmental Psychology, 25(6), 667-84.

van Hiel, A., Pandelaere, M., \& Duriez, B. (2004). The impact of need for closure on conservative belief and racism: Differential mediation by authoritarian submission and authoritarian dominance. Personality and Social Psychology Bulletin, 30(7), 824-37. 
van Zomeren, M., Spears, R., Fischer, A.H., \& Leach, C.W. (2004). Put your money where your mouth is! Explaining collective action tendencies through group-based anger and group efficacy. Journal of Personality and Social Psychology, 87(5), 649-64.

von Hippel, W., Sekaquaptewa, D., \& Vargas, P.T. (2009). Linguistic markers of implicit attitudes. In Petty RE, Fazio RH and Brinol P (eds) Attitudes: Insights from New Implicit Measures. New York: Psychology Press.

Weatherby, G.A., \& Scoggins, B. (2010) A content analysis of persuasion techniques used on white supremacist websites. Journal of Hate Studies, 4(1), 9.

Weaver, S. (2012). A rhetorical discourse analysis of online anti-Muslim and anti-Semitic jokes. Ethnic and Racial Studies, 36(3), 483-99. 
Table 1 Linguistic differences between racist self-descriptions and neutral comparison texts

\begin{tabular}{|c|c|c|c|c|}
\hline Category & Examples & $T$ & Df & Cohen's $d$ \\
\hline \multicolumn{5}{|l|}{ Personal pronouns } \\
\hline 1st pers singular & $\mathrm{I}$, me, mine & -128.45 & 237.86 & $-2.76^{* * *}$ \\
\hline 1st pers plural & We, us, our & 11.90 & 101.37 & $1.51 * * *$ \\
\hline 2nd person & You, your, thou & -8.28 & 109.14 & $-0.49 * * *$ \\
\hline 3rd pers singular & She, her, him & -26.40 & 137.69 & $-0.87 * * *$ \\
\hline 3rd pers plural & $\begin{array}{l}\text { They, their, } \\
\text { they'd }\end{array}$ & 4.97 & 102.40 & $0.52 * * *$ \\
\hline $\begin{array}{l}\text { Cognitive } \\
\text { complexity }\end{array}$ & & & & \\
\hline $\begin{array}{l}\text { Composite cognitive } \\
\text { complexity }\end{array}$ & $\begin{array}{l}\text { zexcl }+ \text { ztentat }+ \\
\text { znegate }+ \\
\text { zdiscrep - zincl }\end{array}$ & -13.73 & 104.77 & $-1.08 * * *$ \\
\hline Exclusive & $\begin{array}{l}\text { But, without, } \\
\text { exclude }\end{array}$ & -8.74 & 105.42 & $-0.65 * * *$ \\
\hline Tentative & $\begin{array}{l}\text { maybe, perhaps, } \\
\text { guess }\end{array}$ & -10.90 & 104.92 & $-0.85 * * *$ \\
\hline Negations & No, not, never & -9.28 & 106.56 & $-0.64 * * *$ \\
\hline Discrepancy & $\begin{array}{l}\text { should, would, } \\
\text { could }\end{array}$ & -3.87 & 103.31 & $-0.36^{*}$ \\
\hline Inclusive & $\begin{array}{l}\text { And, with, } \\
\text { include }\end{array}$ & 10.09 & 102.88 & $0.98 * * *$ \\
\hline Insight & $\begin{array}{l}\text { think, know, } \\
\text { consider }\end{array}$ & -2.59 & 104.82 & -0.20 \\
\hline
\end{tabular}


Personal concerns

\begin{tabular}{|c|c|c|c|}
\hline Religion & Altar, church, & 8.02 & 101.13 \\
\hline
\end{tabular}

$\begin{array}{llll}\text { Death } & \text { Bury, coffin, kill } & 3.41 & 102.07\end{array}$

$\begin{array}{lllll}\text { Money } & \text { Audit, cash, owe } & 3.29 & 102.69 & 0.33\end{array}$

\section{Emotions}

$\begin{array}{llll}\text { Affective processes } & \text { Happy, cried, } & 0.94 & 105.24\end{array}$ abandon

$\begin{array}{llll}\text { Positive emotion } & \text { Love, nice, sweet } & -0.29 & 105.08\end{array}$

$\begin{array}{llll}\text { Negative emotion } & \text { Hurt, ugly, nasty } & 1.73 & 103.92\end{array}$

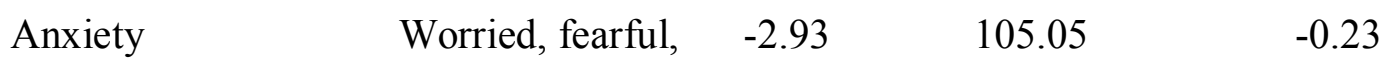

nervous

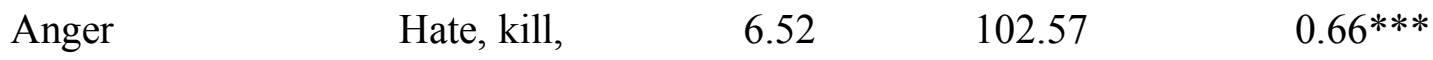

annoyed

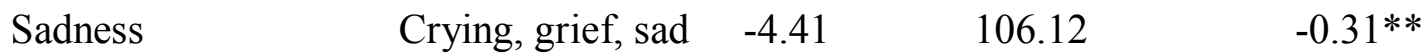

Note: Positive $t$ and $d$ values indicate the mean was higher in racist texts than comparison texts.

$* p<.05, * * p<.01, * * * p<.001$. 